\title{
THE SOCIO-ECONOMIC REALITY OF BEING A DAY LABOURER IN PRETORIA $^{1}$
}

\section{PF Blaauw, AM Pretorius, H Louw, CJ Schenck}

\section{INTRODUCTION}

Day labourers are workers who wait on street corners or in other public places for opportunities to work. They are individuals who work for different employers and get paid on a daily basis. Because they are excluded from the formal labour market, these workers often work for different employers each day, are paid in cash, and do not enjoy benefits such as health insurance and unemployment benefits. It is mainly the employers who benefit from this relationship. They do not have many commitments towards these workers and use them only when work is available.

The day-labour market is a worldwide phenomenon. The characteristics of a typical day labourer leave these workers vulnerable. Immigrants (both legal and illegal) often accept low wages. Day labourers with low education and skills levels are willing to perform dangerous tasks (United States General Accounting Office, 2002:11). A study which was conducted by the National Day Laborers' Organizing Network (n.d.:2-3) reports that day labourers in the United States complained that their employers made them work long hours (eight to 10 and even 12 per day) without allowing them a break or rest. The same respondents were expected to perform dangerous tasks such as small-scale construction and landscaping. Apart from these work-related abuses, many also complained about verbal abuse and sexual harassment (National Day Laborers' Organizing Network, n.d.:7).

In the USA these workers are much more organised than their South African counterparts. The National Day Laborers' Organizing Network (NDLON) was founded in 2000 to enhance collaboration between local day-labourer organising groups in the USA. In South Africa an organisation called "Men on the side of the road" was founded in Cape Town in 1999 and its activities have recently been extended to other regions such as Johannesburg.

The high levels of long-term unemployment in South Africa force more and more people to venture into the informal sector to raise income (Whiteford \& Van Seventer, 1999:3). Thousands of unemployed people stand at the side of the road for an average of between six and seven days per week, waiting for informal and (in most cases) temporary employment. They are willing to do anything - from garden work to mixing cement, painting, and loading or unloading heavy goods. They do it because it is the only income they have. Many days go by without any work for many of these men. A working week of six, sometimes seven, days per week puts a large strain on the quality of their family and social life. This is the harsh reality of their lives.

They receive an average daily wage of between R50 and R60 for a long day 's work. Apart from the low wages that they earn, the workers are faced with great instability in terms of the wages that they earn in a good month and a bad month. Extensive research on the activities and contribution of this labour market has been done in the United States. Similar research in South Africa has only started to gain momentum. This paper contributes to the scientific knowledge on this growing labour market in a country with high levels of unemployment.

${ }^{1}$ A previous version of this paper was delivered at the $28^{\text {th }}$ CIRET (Centre for International Research on Economic Tendency) Conference, Rome, Italy, 20-23 September 2006. The authors are grateful for the generous financial assistance that was provided by the Thuthuka Fund of the NRF to facilitate the completion of the research project. 
The aim of this paper is to provide an overview of the circumstances which day labourers, and their families, have to face in Pretoria. The results of this study are compared with studies on the day-labour market that were done in the United States. Some of the results are analysed and compared with trends that have been observed internationally and conclusions are drawn on the social impact of this activity.

\section{RESEARCH METHODOLOGY}

The research project took the form of a detailed survey-based study that was conducted among day labourers in the greater Pretoria region. According to Rubin and Babbie (1997:346), surveys can be used for exploratory, descriptive and explanatory purposes. The survey in this research served the purpose of all three these elements. In order to ensure that there were no misunderstandings and misinterpretations of questions, the survey was conducted by means of structured interviews (Bless \& Higson-Smith, 1995:111). This means that the questions were explained thoroughly to the respondents.

The research process started with a thorough literature study on the topic. Academic literature in South Africa on the subject is scarce. Schenck and Louw (2005) did the first exploratory study of this nature in Elardus Park in Pretoria. Gonzo and Plattner (2003) did a study among day labourers in Windhoek, Namibia. In terms of the working conditions, educational qualifications and income of day labourers, their findings were much the same as those of Schenck and Louw. An important comparable international study is the one that was conducted in the United States by Valenzuela Jr, Theodore, Meléndez and Gonzalez (2006). Most of the other literature that was used was in the form of various newspaper articles, mainly in the local newspaper and occasionally in the daily press.

The study by Schenck and Louw (2005) provided the platform for the formulation of the questionnaire for the envisaged research project, which was to involve the whole of Pretoria. Several planning meetings were held at the Department of Social Work at the University of South Africa. The questionnaire for the survey was designed by using the methodology that had been followed in a similar study in the United States (Valenzuela Jr et al., 2006) as a basis. The questionnaire contained questions regarding the demographic features, working conditions and possible abuse of day labourers.

Suitable fieldworkers were recruited among third-year and postgraduate students in the Department of Social Work at the University of South Africa. Twenty students were hired to act as fieldworkers for the study. One of the important criteria for their selection was the ability to communicate with respondents in English and at least another African language. The selected fieldworkers underwent appropriate training under the guidance of two of the authors over a period of two days. The questionnaire was then tested in the form of a trial run. The comments of the fieldworkers were taken into account and the questionnaire was improved.

The size of the research population was determined through a proper reconnaissance of the various hiring sites in the Pretoria area. From the research population of an estimated 2500 day labourers in Pretoria, a sample population of about $10 \%$ was included in the survey. The various hiring sites were therefore classified according to the number of workers who stood at each site: 37 sites were identified as small sites (1-25 people); 21 were medium sites (26-50 people); nine were large sites (51-100 people); and two were mega sites (more than 100 people). The research population was allocated proportionally between the various hiring sites (i.e. in terms of the size of the sites) before a representative sample of 240 workers who would be interviewed was decided upon. 
The fieldworkers conducted the fieldwork from the $27^{\text {th }}$ to the $30^{\text {th }}$ of September 2004, beginning as early as 06:00 in the morning. Overall, the attitude of the respondents was positive. During the interviews a total of 242 questionnaires (about $10 \%$ of the research population) were satisfactorily completed for the sample population.

\section{PROFILE OF DAY LABOURERS IN PRETORIA}

Table 1 provides a summary of the results of the survey that was conducted among day labourers in Pretoria. It describes the demographic features, working conditions and income of the day labourers.

TABLE 1

PROFILE OF DAY LABOURERS IN PRETORIA

\begin{tabular}{|l|l|}
\hline \multicolumn{1}{|c|}{ Feature } & \multicolumn{1}{|c|}{ Value } \\
\hline Gender & $97.5 \%$ Male \\
& $2.5 \%$ Female \\
\hline Origin & $88 \%$ born in South Africa \\
& $7 \%$ born in Zimbabwe \\
& $2.9 \%$ born in Mozambique \\
& $2.1 \%$ did not want to specify country of birth \\
\hline Age & Almost 75\% are younger than 35 \\
& $61.2 \%$ are younger than 30 \\
\hline Dependants & Average 4.24 \\
\hline School education & $5 \%$ never attended school \\
\hline Tertiary education & $14 \%$ passed Grade 12 \\
\hline Other formal after-school training & None \\
\hline Days per week worked as day & $51.2 \%$ between $1-2$ days \\
labourer & $19.8 \% 7$ days \\
\hline Income in a good month & Average: R 1187.46 \\
\hline Income in a bad month & Average: R 401.93 \\
\hline Income in August 2004 & Average: R 672.17 \\
\hline Source: Survey data &
\end{tabular}

Source: Survey data

All the day labourers in the survey were black and they were almost exclusively male. Only six women day labourers were among the respondents. The gender distribution is to a large extent explained by the unprotected nature of the lives that day labourers lead. Most were born in South Africa, followed by Zimbabwe and Mozambique. Some respondents did not want to specify their country of birth. It can be expected that these men were born outside South Africa.

An interesting statistic is that as many as 215 (or 88.8\%) of the day labourers who were interviewed came from outside the Gauteng province to seek employment in Pretoria. Almost $60 \%$ of the day labourers came from the Limpopo and Mpumalanga provinces. This trend corresponds to the fact that a significant percentage of the respondents were born in Zimbabwe and Mozambique, and they use the provinces that are closest to these countries as their port of entry into South Africa. Limpopo and Mpumalanga are regarded as the poorer provinces in South Africa (Blaauw, Louw \& Schenck, 2005:28-31). 
On average, each day labourer supports 4.24 people (including himself) with the income he earns in this informal labour market. More than half of the respondents (56.2\%) supported up to four people, while $4.1 \%$ of the respondents indicated that they supported more than nine people with their income. By using the frequency results of the questionnaire, it is estimated that the informal labour market of day labourers provides some income for at least 10000 people $^{2}$ (Blaauw et al., 2005:28-31).

The day labourers who were interviewed for this survey had low levels of formal schooling. This has a definite impact on their chances of obtaining a position in the formal sector of the labour market. Lack of financial support was cited as the main reason for their leaving school. The rest of the research population listed failing, lack of interest and various other reasons for leaving school.

In general the skills level of day labourers is very low. As many as 99 (40.9\%) admitted to having no formal training whatsoever. Although the other respondents suggested training in the fields of painting $(13.6 \%)$, the security business $(8.7 \%)$, carpentry $(5 \%)$ and various other areas, no details on any formal qualification or completion of an apprenticeship were available.

The survivalist nature of this informal labour market is clearly illustrated by the long periods that these people stand and wait in the hope of finding employment. This puts a lot of strain on the social fabric of the community where these people live. Having little time for relaxation and family does not augur well for the quality of life of the people in this industry (Blaauw et al., 2005:28-31).

Day labourers experience large variances in the income that they earn. This is evident from the huge difference between the income that they earn in a good month and the amount they earn during a bad month. This uncertainty has a huge impact on the ability of day labourers to plan ahead. The fieldwork brought this uncertainty to the fore when the respondents expressed anxiety in terms of whether or not they would be able to support their dependants each month. An analysis of the income earned by day labourers shows that most of them struggle to support their dependants even in months that can be classified as extremely good in terms of income earning possibilities (Blaauw et al., 2005:28-31). This trend is also observed internationally. Valenzuela Jr et al. (2006:11-12) state:

"The volatility of monthly earnings can best be observed by comparing the earnings distribution of day laborers' peak (i.e. good months) and slow (i.e. bad months) periods. The median earnings level in a good month rises to $\$ 1,400$. However in a bad month, median earnings fall to just 36 percent of peak period levels, or $\$ 500$. Therefore, even in cases where day labourers have many more good months than bad months, it will be unlikely that their annual earnings will exceed $\$ 15,000$, keeping most workers in this market at or below the federal poverty threshold."

\section{CIRCUMSTANCES THAT DAY LABOURERS IN PRETORIA HAVE TO FACE}

\section{Family ties}

Family ties were important for the day labourers in Pretoria. The fieldwork showed this quite clearly. Thirty-three percent were married under either customary or common law and $6 \%$ lived

\footnotetext{
${ }^{2}$ This number was calculated by using the number of people in each category of Table 1 multiplied by the value in the category and then added together. As the sample represents $10 \%$ of the total population, the obtained value was multiplied by 10 in order to determine the final estimate.
} 
with a partner. Only $3.7 \%$ were separated or divorced. In short, day labourers have families that need maintenance and support. Given the level of income that they earn, day labourers share a common concern in terms of their ability to support their relatives and other dependants.

Unfortunately, a lot of the people in this labour market activity do not live with their immediate family and dependants. Many of them spend most of the year in Pretoria, attempting to earn enough money to send home as a first priority and - if their income allows it - to go home themselves. These two aspects are often mutually exclusive. The research showed that many of the day labourers did not see their families regularly. Sixty-four of the respondents $(30.5 \%)$ only visited their families once or twice a year, while $26(12.4 \%)$ were able to go home once every quarter. For monthly, weekly and daily visits, the numbers are $27.1 \%, 6.2 \%$ and $23.8 \%$ respectively.

Even if these people are not able to visit their families as often as they would like to, they do endeavour to send money to their dependants. On a question as to how often during the last 12 months they were able to send money home, their responses indicated that a third of them $(33.8 \%)$ were able to send money home only once or twice a year. The most frequently that money was sent home was 3 to 6 times a year $38.8 \%$ of the day labourers said that this was their experience). Only $22.7 \%$ of the respondents were able to send money home between 7 and 12 times per year. The majority of them (40.3\%) choose to deliver the money in person. Other methods of delivery (such as using the Post Office, banks, friends or relatives) were used in more or less equal measure by the rest of the respondents. It will come as no surprise that in $88.5 \%$ of the cases, the money was delivered to their immediate families (with relatives and friends making up the rest of the categories).

Figure 1 provides an indication of the amounts of money that day labourers were able to send home during the 12 months that preceded the interviews.

Just over $30 \%$ of the respondents were able to send more than R1 900 to their relatives in the 12 months before the interviews. This might seem encouraging in terms of the proportion of the day labourers who were able to do that. However, one should remember that if this is the only income that their dependants received, they would have been in serious jeopardy, given the minimum level of income that is required to survive in South Africa. Blaauw et al. (2005:29) determined that it is doubtful whether day labourers are able to support their dependants even in months that can be classified as good in terms of income-earning possibilities. Figure 1 shows that as many as $38.2 \%$ of the day labourers were only able to send less than R700 to their dependants in the previous 12 months. We therefore believe that other governmental grants and transfer payments play an important role in the survival of the dependants of day labourers. 
FIGURE 1

AMOUNT OF MONEY THAT DAY LABOURERS IN PRETORIA WERE ABLE TO

SEND HOME

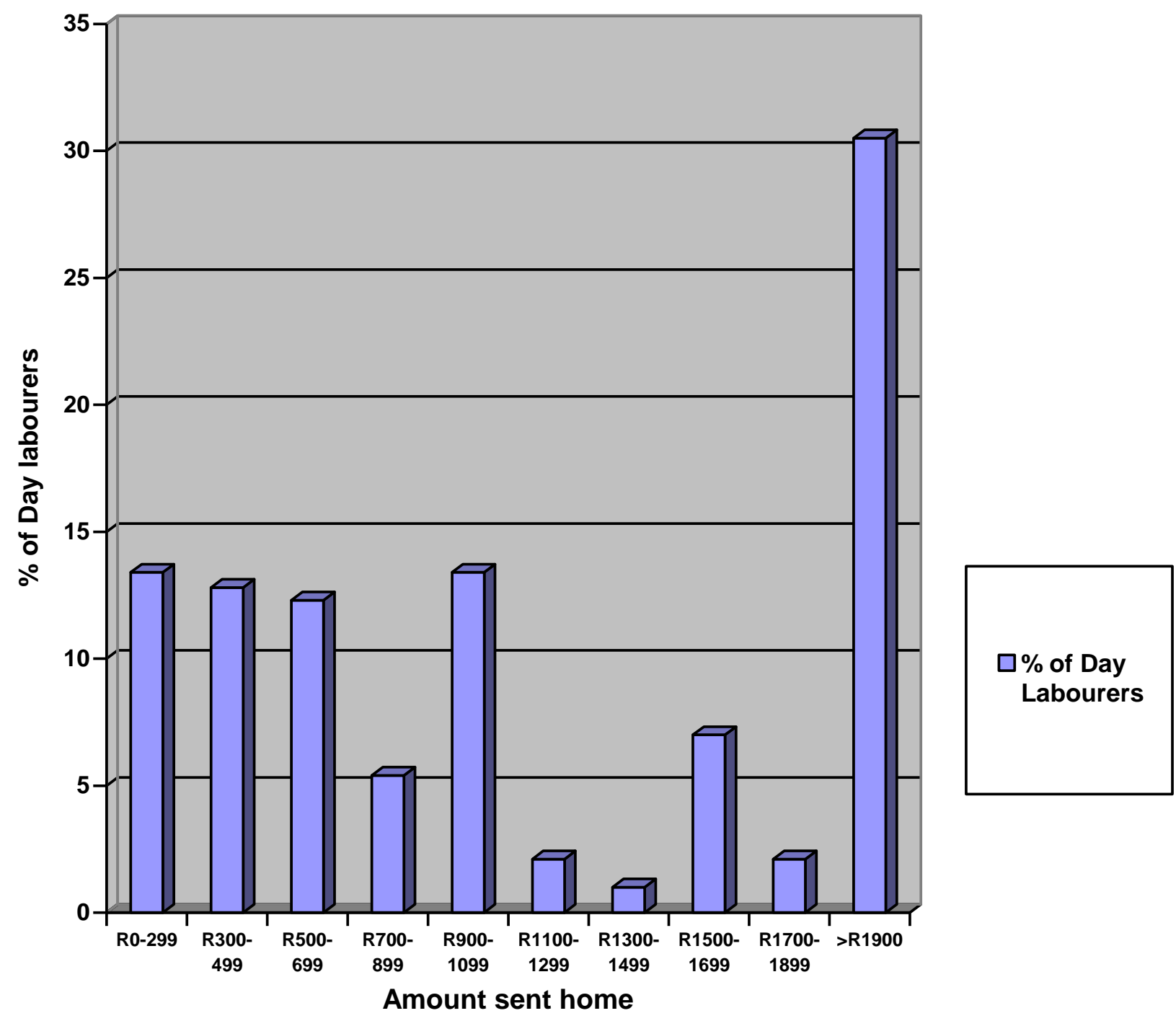

Source: Survey data

\section{Individual circumstances of day labourers in Pretoria}

The people who were involved in this study lead harsh lives in which many were separated from family members for long periods of time. This raises the question as to what their individual circumstances are like. Various questions in the survey were designed to obtain information regarding this aspect of the day labourers' lives. The respondents were asked where they sleep at night and their responses were varied. Fifty-six of the men (a significant 23.2\%) slept in a residence with more than one room in it. These were in most cases the same men who saw their families on a regular basis. The situation was unfortunately not as good for many of their counterparts. Fifty-nine of the day labourers (24.5\%) slept in backyard rooms and $57(23.7 \%)$ took shelter in shacks in informal settlements. Other sources of lodging included hostels $(12 \%)$; the open veld/bushes (7.5\%), construction sites (4\%) and one man maintained that he slept in the street. 
At first glance, the circumstances under which many of these labourers live seem to be unsafe. The reality is that the vast majority - ranging from $198(82.2 \%)$ to 212 responses (88\%) maintained that they were never insulted, threatened, assaulted, harassed by the police or robbed where they slept at night.

\section{TABLE 2}

MONTHLY SPENDING ON LODGING

\begin{tabular}{|l|l|c|c|}
\hline \multicolumn{1}{|c|}{ Amount spent } & $\begin{array}{c}\text { \% of average } \\
\text { income }\end{array}$ & $\begin{array}{c}\text { Number of day } \\
\text { labourers }\end{array}$ & \% of day labourers \\
\hline$<$ R50 & $<7.4 \%$ & 149 & $61.6 \%$ \\
\hline R50-R99 & $7.4 \%-14.7 \%$ & 30 & $12.4 \%$ \\
\hline R100-R199 & $14.9 \%-29.6 \%$ & 38 & $15.7 \%$ \\
\hline R200-R299 & $29.8 \%-44.5 \%$ & 20 & $8.3 \%$ \\
\hline$>$ R300 & $>44.6 \%$ & 5 & $2.1 \%$ \\
\hline
\end{tabular}

Source: Survey data

Table 2 provides a summary of the main results regarding the cost of lodging for the day labourers. A hundred and forty-nine of the respondents (61.6\% of the total sample) paid less than R50 per month for their accommodation. If we consider that these men earned an average of R672.17 per month, R50 accounts for 7.4\% of their total income. Thirty (12.4\%) of the men paid between R50 and R100 per month for the place where they slept; $38(15.7 \%)$ and $20(8.3 \%)$ men paid from R100 to R199 and from R200 to R299 per month respectively. Only five (2.1\%) of the men paid more than R300 per month for a place to sleep. This is more than $44.6 \%$ of their monthly income. In hindsight it would have been useful to determine the exact amount and whether it referred to rent or ownership.

The position in terms of the food security of these men was also not ideal. The data show that as many as 121 of the day labourers in the sample sometimes did not have enough to eat. This is a significant $50 \%$ of the people who were interviewed. Seventy-seven (31.8\%) men were slightly better off because they had enough to eat, although not always the kind of food that they preferred. Only $38(15.7 \%)$ of the day labourers said that they had enough food that they actually preferred. Six people refused to answer this question and they might very well be part of one of the first two categories.

\section{Work-related injuries}

Kerr and Dole (2001:16) reported on the level of worker safety in the city of Cleveland in the United States. According to their study, $70 \%$ of day labourers work in unsafe working environments. Thirty-nine percent of the day labourers who were interviewed suffered a worksite injury at some stage. Some of these injuries were left untreated and even unreported, because the labourers feared that they would not be paid (Kerr \& Dole, 2001:18). A recent national day labourer survey (Valenzuela Jr et al., 2006:12) reveals that $73 \%$ of all day labourers in the USA considered their jobs to be dangerous. Twenty percent of the 2660 respondents had suffered an injury while working. Two thirds of the respondents had missed work due to an injury. Of the injured, 39\% missed a week or less of work; 39\% lost between one and four weeks of work; and $22 \%$ missed more than a month of work. More than half of the day labourers who suffered an injury did not receive the medical care they needed. The overwhelming explanation for this is that the worker could not afford the medical treatment and the employer did not want to cover the expenses under workers' compensation insurance (Valenzuela Jr et al., 2006:13). 
In general, the picture in Pretoria resembles that of the USA. Twenty-four percent of the respondents who answered this question did in fact suffer a work-related injury. Of the injured, $57.6 \%$ did not receive the medical care they deemed necessary; $27.1 \%$ indicated that they received medical care in some instances, while only $15.3 \%$ always received the necessary medical care. The most popular answer to the question as to why the particular injury was not treated was that the day labourer could not afford the medical treatment $-46.2 \%$ of the relevant respondents gave this answer. Two of the 56 respondents indicated that they did not know where to go for medical help. Only one respondent blamed it on transport problems.

A total number of 136 cases were recorded where work-related injuries were in fact treated. In the majority of these cases $(28.7 \%)$ the bill was paid by the day labourer himself or his family/friends. Surprisingly, if you consider the results in the USA, 20.6\% of the treatments were paid by the employer or his company and $11 \%$ of the bills were covered by workers' compensation insurance.

Of the 242 respondents, $202(83.5 \%)$ indicated that they did not miss any work day because of injury. This is much more than the mere one third of the day labourers who were interviewed in the USA. Of those that did lose some time, $47.5 \%$ lost a week or less; $27.5 \%$ lost between one and four weeks; and 25\% lost more than a month. Compared to the survey results in the USA, fewer day labourers in Pretoria suffered work-related injuries and those who were injured missed fewer work days than their USA counterparts.

\section{Social network/support among day labourers in Pretoria}

The level of social support is very important in coping with the various negative effects of long spells of unemployment. Unemployed men often view their current situation as a loss of social status. This might lead to their avoiding contact with friends because of shame and therefore reduces the potential for social support (Gonzo \& Plattner, 2003:26).

Because day labourers are separated from their immediate families for long periods of time, it is important to determine to what extent they form social groups that provide them with support in various aspects of their everyday reality. Social resources reduce the negative consequences of stressful events and can help to maintain the psychological and physical wellbeing of people (Gonzo \& Plattner, 2003:26). Standing at the side of the road, hoping to obtain employment that is vital to support dependants who are not even close by, certainly qualifies as an example of such an event.

The survey showed that $147(64 \%)$ of the day labourers were part of a group of day labourers who supported one another. The reasons that the day labourers gave as to why they chose the particular group included the following in descending order of importance: originating from the same place, speaking the same language, faith, sport interest, family relations and age. These men relied on other day labourers for assistance with a number of aspects of their everyday lives.

Table 3 indicates the various areas of assistance that day labourers rely on other day labourers and also the number and percentage of day labourers who received assistance in a particular area.

The importance of social aspects such as religion is highlighted by the fact that as many as 153 day labourers (representing $65.4 \%$ of the sample) said that they belonged to or attended religious gatherings. The corresponding figure for the United States was 52\% (Valenzuela $\mathrm{Jr}$ et al., 2006:iii). 
TABLE 3

AREAS OF ASSISTANCE PROVIDED IN SOCIAL GROUPS

\begin{tabular}{|l|c|c|}
\hline Area of assistance & Number of day labourers & Percentage of day labourers \\
\hline Finding work & 176 & $72.7 \%$ \\
\hline Transport/lifts & 82 & $33.9 \%$ \\
\hline Loans & 102 & $42.1 \%$ \\
\hline Favours & 143 & $59.1 \%$ \\
\hline Food & 143 & $59.1 \%$ \\
\hline Shelter/housing & 87 & $36.0 \%$ \\
\hline Social life & 153 & $63.2 \%$ \\
\hline Care when sick & 137 & $56.6 \%$ \\
\hline Family matters & 99 & $40.9 \%$ \\
\hline Other & 29 & $12.0 \%$ \\
\hline
\end{tabular}

Source: Survey data

However, the number of day labourers who belonged to or went to a sports club/organisation shows a marked decrease. Only $110(47 \%)$ responded in the affirmative to this question. This result is not surprising given the fact that the majority of the day labourers stand at the side of the road for five to six days per week in the hope of getting temporary employment. Even more importantly, belonging to a sport club or organisation usually requires membership fees. The relatively low and variable level of income that they earn makes this very difficult to maintain. What is surprising is that this figure is still more than double that of the day labourers in the United States, where only 22\% were involved in a sport club (Valenzuela Jr et al., 2006:iii).

The day labourers viewed the idea of a formal day-labour centre or hiring hall in a positive light. Almost three quarters (73.4\%) of them indicated that they would use such a facility if it were available. This, again, is the opposite of the results of similar studies that were done in the United States. According to Valenzuela Jr et al. (2006:i), only one in five (21\%) day labourers searched for work at day-labour worker centres. Worker centres have, however, emerged in the United States as the most comprehensive response to the challenges that are presented by an increase in the number of day labourers (Valenzuela Jr et al., 2006:iii). This figure may therefore very well increase in future as a result.

\section{CONCLUSION}

Family ties were important for the day labourers in Pretoria. The family structures of individual respondents differed considerably and thus they enjoy varying levels of support. The $23.2 \%$ of respondents who indicated that they lived at home corresponds to the $23.8 \%$ who saw their family on a daily basis. These day labourers lived at home and were part of family units, with the expected support and socialisation. However, roughly one third of the respondents visited their families only once or twice a year. They did manage to send money home, although not enough to sustain any household. We therefore concluded that other governmental grants and transfer payments play an important role in the survival of day labourers' dependants. Although most of the men were physically removed from their families, they deemed them important enough to try to maintain ties with them.

While they are away from home and separated from their families, most of them sleep in backyard rooms and shacks in informal settlements. These men rely on their fellow day labourers for social support and interaction. Sixty-four percent of the respondents indicated that they were 
part of a group of day labourers who supported each other. Apart from helping each other to find work, they also supported each other in terms of their social life, performed favours, shared food and took care of each other when sick. Their need for social interaction is further illustrated by the two thirds who belonged to religious groups and almost 50\% who were members of sport organisations, despite their poverty. This is almost double the number of day labourers in the USA who belonged to such organisations.

The socio-economic circumstances which day labourers in Pretoria have to face correlate well with the experience of day labourers in the United States. Proper policy formulation cannot take place if these are not factored into the equation. Further research, preferably in the form of countrywide interviews, is necessary to provide the information that is required for the above to take place.

\section{REFERENCES}

BLAAUW, P.F., LOUW, H. \& SCHENCK, C.J. 2005. The dynamics of informal labour markets in South Africa - a case study of day labourers in Pretoria. Department of Economics Research Paper No. 0501, University of Johannesburg.

BLESS, C. \& HIGSON-SMITH, C. 1995. Fundamentals of social research methods - an African perspective $\left(2^{\text {nd }}\right.$ ed $)$. Cape Town: Juta.

GONZO, W. \& PLATTNER, I.E. 2003. Unemployment in an African country: A psychological perspective. Windhoek: University of Namibia Press.

KERR, D. \& DOLE, C. 2001. Challenging exploitation and abuse: A study of the day labor industry in Cleveland. Cleveland: City Council.

NATIONAL DAY LABORERS' ORGANIZING NETWORK (NDLON). n.d. Common ground. A study conducted by the National Day Laborers' Organizing Network, written in conjunction with Sue McCarty and George Faraday, University of Maryland School of Law Labor Law Clinic.

RUBIN, A. \& BABBIE, E. 1997. Research methods for social work. Pacific Grove: Brooks Cole.

SCHENCK, R. \& LOUW, H. 2005. An exploratory study on day labourers in Elardus Park Pretoria. Social Work/Maatskaplike Werk, 41(1):84-95.

UNITED STATES GENERAL ACCOUNTING OFFICE (GAO). 2002. Worker protection. Labor's efforts to enforce protections for day laborers could benefit from better data and guidance. GAO-02-925, September.

VALENZUELA JR., A., THEODORE, N., MELÉNDEZ, E. \& GONZALEZ, A.L. 2006. On the corner: Day labour in the United States. Los Angeles: UCLA.

WHITEFORD, A. \& VAN SEVENTER, D.E. 1999. Winners and losers: South Africa's changing income distribution in the 1990s. Menlo Park: WEFA Southern Africa.

Derick Blaauw, Senior Lecturer, Department of Economics, University of Johannesburg, Johannesburg, South Africa; Anmar Pretorius, Senior Lecturer, Department of Economics, University of South Africa, Pretoria, South Africa; Huma Louw, Lecturer, Department of Social Work, University of South Africa, Pretoria, South Africa; Rinie Schenck, Associate Professor, Department of Social Work, University of South Africa, Pretoria, South Africa. 